\title{
Notas sobre a Evolução do Mercado de Trabalho no Brasil
}

\author{
On the Evolution of the Brazilian Labor Market
}

CLÁUDIO SALVADORI DEDECCA ${ }^{1}$

RESUMO: Desde 1990, o problema do emprego no Brasil tem sido associado ao modelo de regulação das relações de trabalho em um contexto de internacionalização e reorganização da economia nacional. Essa perspectiva propõe a flexibilidade do modelo de proteção social estabelecido na Constituição Nacional. Este ensaio tem como objetivo apontar que o problema nacional do emprego não se explica pelo modelo atual de regulação social. É produto do processo de formação e regulação do mercado de trabalho estabelecido nos anos 40 do século passado e da maneira como esse processo se articulou com uma trajetória particular de desenvolvimento da economia brasileira no período 1930-1980. Nos últimos 20 anos, a estagnação da economia brasileira em um contexto de reorganização da estrutura produtiva agravou o problema do emprego.

PALAVRAS-CHAVE: Emprego; desenvolvimento sócio-econômico; desemprego; mercado de trabalho.

ABSTRACT: Since 1990, the problem of employment in Brazil has been associated to the model of regulation of the labor relations in a context of internationalization and reorganization of the national economy. This perspective proposes the flexibility of the model of social protection established in the National Constitution. This essay has the objective to point that the national problem of employment doesn't explain by the actual social regulation model. It is product of the process of formation and regulation of the labor market established in the 40's of the last century and of the way as this process was articulated with a particular trajectory of development of the Brazilian economy in the period 1930-80. In the last 20 years, the stagnation of the Brazilian economy in a context of reorganization of the productive structure has aggravated the employment problem. KEYWORDS: Employment; social-economic development; unemployment; labor market. Jel Classification: J23, P21, O54.

\footnotetext{
${ }^{1}$ Professor do Instituto de Economia da Universidade Estadual de Campinas - Unicamp, Campinas-SP, Brasil. E-mail: cdedecca@eco.unicamp.br. Submetido: outubro 2003; aceito: fevereiro 2004.
} 
A tendência recorrente de crescimento do desemprego no capitalismo avançado e em desenvolvimento, observada nesses quase últimos trinta anos, tem sido acompanhada por uma crescente complexidade do debate sobre o problema de geração de emprego (Sorrentino, 1993). De uma visão focada na situação do desemprego aberto, o debate progrediu para um enfoque bastante mais abrangente, que foi acompanhado de uma forte polarização das interpretações existentes sobre o problema. De um lado, aparece toda uma linha de análise que busca desqualificar boa parte das situações de falta de trabalho, no sentido de provocar uma convergência de sua dimensão àquela circunscrita ao desemprego aberto. De outro, uma linha de análise procura apontar que a recorrência da falta de trabalho associa-se à emergência de formas diversas de manifestação do problema, que se afastam daquela caracterizada pelo desemprego aberto. Assim, teria se consolidado, durante o período, um crescente distanciamento entre o desemprego total e o desemprego aberto.

Se, em um primeiro momento, o debate sobre o tema privilegiou a mensuração do problema, nota-se, em seguida, que o resultado desse esforço tem justificado interpretações sobre o papel atual da política social e dos sistemas nacionais de relações de trabalho, bem como de possíveis mudanças dos mesmos.

Para que se possa analisar a questão no contexto brasileiro, esse ensaio discute o problema de geração de emprego a partir da década de 80, procurando apontar suas relações com as novas condições de funcionamento da economia brasileira, mas também seu condicionamento pelas características estruturais de formação do mercado e das relações de trabalho no país.

\section{O PROBLEMA DE EMPREGO NO DESENVOLVIMENTO SÓCIO-ECONÔMICO BRASILEIRO}

É impossível tratar do trabalho no Brasil sem considerar alguns aspectos relevantes do processo de formação do mercado e das relações de trabalho no país. Como veremos, esse processo continua condicionando o problema atual de emprego e renda no Brasil.

O primeiro aspecto a ser tratado diz respeito ao movimento de transição do trabalho escravo para o trabalho livre. Isto é, do estabelecimento do mercado de trabalho a partir de meados do século XIX. As características desse processo explicam a recorrente abundância de força de trabalho disponível para o processo de industrialização conhecido pelo país durante o século XX.

Antes mesmo da abolição do trabalho escravo, ocorrida tardiamente na década de 80 do século XIX, o Império estabeleceu duas leis que condicionaram a constituição do mercado de trabalho livre.

Em 1850, uma Lei dispôs sobre a titulação da terras ocupadas, definindo a propriedade privada das mesmas. Essa regulamentação reconheceu a propriedade das terras do regime de sesmarias, devendo as demais ser destinadas pelo Estado à propriedade privada, através de uma compensação financeira estipulada pelo mesmo. 
Essa particular forma de estabelecimento da propriedade privada garantiu a posse de terras oriunda do ciclo açucareiro e do ouro, as quais incorporavam grande parte da reserva de força de trabalho existente no país. Quando da passagem para o trabalho livre, essa população foi impedida de ter acesso a terra para se ocupar, sendo obrigada a se subordinar ao trabalho no latifúndio. É fato que a ocupação de terras foi observada através de um movimento de ampliação sistemática da fronteira agrícola. Contudo, essa ocupação se fazia de modo precário e sem respaldo legal do Estado, ficando a população exposta recorrentemente à expulsão para as novas zonas de fronteira. Pode-se afirmar que o modo de regulação da propriedade privada da terra impediu o seu acesso aos trabalhadores livres, constituindo-se a raiz do problema agrário no país e o instrumento básico para a subordinação do trabalho (Carvalho Franco, 1983: 186 e 187).

A outra lei que merece menção é a de 1879 , que regula a relação de trabalho no regime de colonato e parceria (Lamounier, 1988). Esse dispositivo garantia ao proprietário da terra romper o contrato de produção de maneira unilateral. A lei reconhecia o caráter privado da relação de trabalho, dando autonomia ao proprietário no estabelecimento do contrato.

A essas duas leis, cabe ainda considerar a política de imigração adotada com o advento da República em 1889.

A expansão cafeeira em direção a São Paulo mostrou rapidamente os limites da disponibilidade local de mão-de-obra. Em face das características do processo de ocupação territorial no período da Colônia, a população brasileira encontravase concentrada em estados da então denominada Região Norte (Pernambuco, Ceará e Bahia) e em dois outros da Sudeste (Rio de Janeiro e Minas Gerais).

$\mathrm{Na}$ Região Sudeste, a concentração das atividades governamentais e de serviços na cidade do Rio de Janeiro reabsorveu, na segunda metade do século XIX, a disponibilidade de mão-de-obra ali existente. De tal modo, a primeira fase da expansão cafeeira no Estado foi suficiente para absorver o excedente de mão-de-obra ainda restante na região. Por outro lado, a disponibilidade encontrada em Minas Gerais propiciou limitadamente sua expansão cafeeira. Assim, constata-se que esse processo, ao encontrar terras de melhor qualidade e um mercado internacional em expansão, esbarrou rapidamente em um problema: o suprimento de mão-de-obra.

Uma possibilidade existente para solucionar essa restrição era a mobilização de população da Região Nordeste para o estado de São Paulo. Afinal, o Censo Demográfico de 1872 informava que a Região Nordeste respondia por quase $50 \%$ da população brasileira. A grande disponibilidade de força de trabalho livre estava ali localizada. Ademais, grande parte dessa população encontrava-se ainda, em sua maioria, vinculada à propriedade latifundiária em decadência do período açucareiro.

A decisão em favor da política migratória em substituição ao processo de mobilização da disponibilidade populacional da Região Nordeste encontra várias explicações na historiografia brasileira.

Uma delas argumenta que a grande dificuldade encontrada para a mobilização dessa população nasceu da presença desses interesses latifundiários na formação 
do Estado Nacional. A mobilização dessa população para São Paulo aceleraria a decadência da propriedade latifundiária nordestina.

Outra perspectiva encontrada afirma que os cafeicultores paulistas desconfiavam que a mobilização serviria para os proprietários nordestinos transferirem a desvalorização do capital empregado com mão-de-obra. Os cafeicultores paulistas consideravam que estariam comprando um "mico" e que posteriormente seriam obrigados a incorporarem a desvalorização do capital empregado com a compra de mão-de-obra escrava.

A última visão encontrada associa a mobilização em favor da migração em contraposição à conformação de um mercado de trabalho livre constituído por trabalhadores negros na Região Sudeste, processo que não encontrava aceitação entre os cafeicultores paulistas.

É fato que, independentemente dos motivos que justificaram as posições políticas existentes, esses interesses atuaram junto ao Estado Imperial e, posteriormente, Federal com o objetivo de impedir ou não chancelar o processo de mobilização de mão-de-obra inter-regiões. Em troca, aceitaram que o Estado central financiasse uma política de migração externa que resolvesse o problema de braços do complexo cafeeiro. Estabeleceu-se um acordo político que orientou a constituição do mercado de trabalho livre no Brasil (Stolcke e Hall, 1983; e Holloway, 1984).

Esse acordo permitiu que a montagem desse mercado se fizesse sem aproveitar a disponibilidade de mão-de-obra existente. Enquanto se organizava um mercado de trabalho livre associado à expansão cafeeira, mantinha-se em situação de latência uma grande disponibilidade de população adulta na Região Nordeste (Furtado, 1977; e Mello e Castro,1984).

Ao contrário dos países europeus, cujos Estados Nacionais forçaram a liberação de mão-de-obra pelas atividades pré-capitalistas, e os Estados Unidos, que mobilizaram a mão-de-obra negra com a Guerra da Secessão, observa-se que o Brasil montou seu mercado de trabalho livre garantindo a preservação das atividades e dos espaços ocupacionais oriundos das fases anteriores de desenvolvimento capitalista do período colonial.

O reflexo dessa política influenciou a distribuição regional da população brasileira durante todo o século XX. Como se observa no Gráfico 1, o aumento das participações de São Paulo e das Regiões Sul e Centro-Oeste não se fizeram acompanhado de uma desaceleração do crescimento populacional das Regiões Nordeste e Sudeste (exclusive o estado de São Paulo).

Somente após 1930, o país começa a integrar tanto as atividades econômicas como o mercado de trabalho. Até então, a unidade política não encontrava qualquer articulação interna na organização de seu sistema econômico. A crise de 1929, ao comprometer o comércio internacional, colocou em questão o complexo cafeeiro, induzindo o desenvolvimento do mercado interno devido às restrições para importação. O início da integração nacional propiciou a quebra da situação de isolamento dos mercados regionais, permitindo o início da mobilização dos trabalhadores nordestinos para o processo de industrialização concentrado na Região Sudeste, em especial no estado de São Paulo (Furtado, 1977; Oliveira, 1975; e Cano, 1990). 
Gráfico 1: Evolução e Distribuição da População Total (Brasil, 1872-2000)

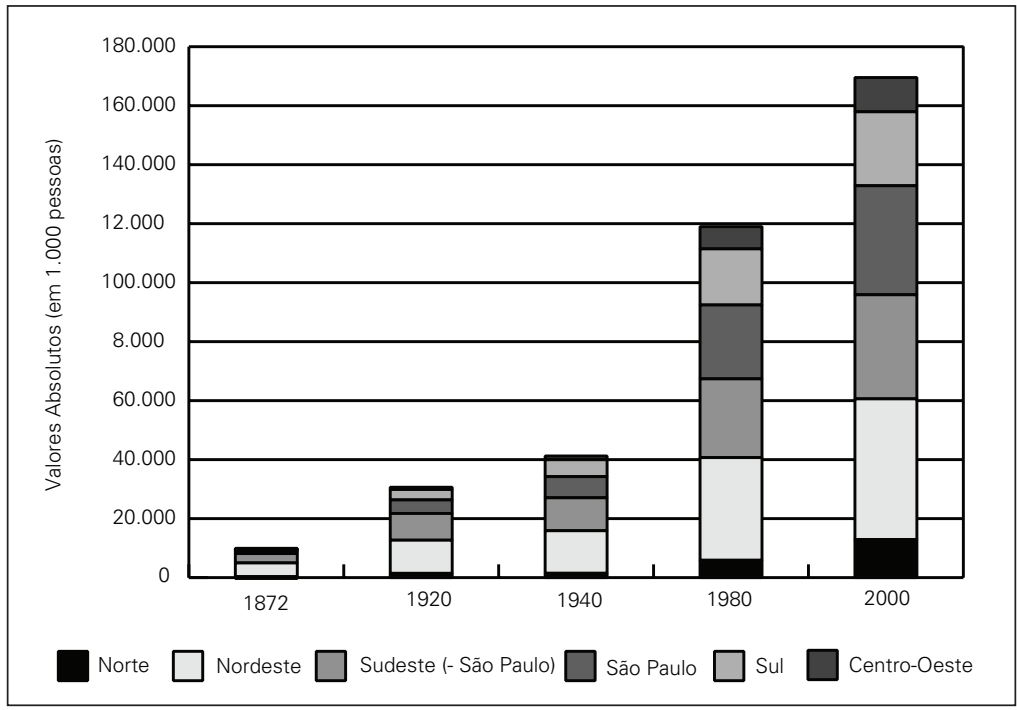

Fonte: Estatísticas Históricas e Censos Demográficos, IBGE. Elaboração do autor.

A manutenção da propriedade privada fundiária, estabelecida nos anos 50 do século XIX, permitiu que a mobilização decorresse de uma migração rural-urbana intensa. Essa migração acabou por ter como destino a Região Sudeste, que, em 1930, já havia a montado seu mercado de trabalho livre e não possuía capacidade de absorver adequadamente essa disponibilidade de mão-de-obra.

Gráfico 2: Evolução da População Ocupada (Brasil, 1940-2000)

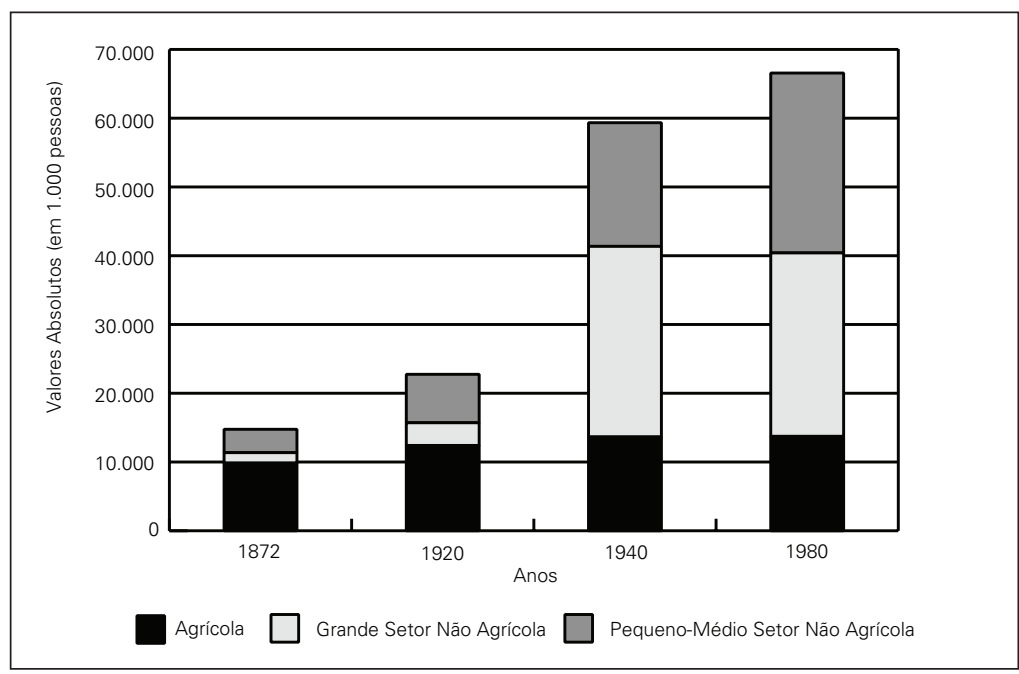

Fonte: Censos Demográficos, IBGE. Elaboração do autor. (1) Estimativa. 
Apesar da elevada capacidade de geração de emprego das atividades industriais e dos novos setores de serviços urbanos públicos e privados, que emergiram com o processo de integração nacional, constata-se que ela se mostrou incapaz de resolver o problema de absorção de mão-de-obra disponível na Região Nordeste. Por esse motivo, a industrialização se fará com elevada e recorrente disponibilidade de força de trabalho.

Esse movimento pode ser rapidamente observado a partir da evolução da população ocupada total, entre 1940 e 1990. Apesar do crescimento elevado da ocupação industrial e das atividades de serviços governamentais e de utilidade pública, que predominaram no Grande Setor Não Agrícola, nota-se a reprodução do estoque de ocupados nas atividades agrícolas e o crescimento ponderável daqueles vinculados ao Pequeno Médio Setor, segmento voltado particularmente para as atividades de consumo pessoal e domiciliar.

Para melhor compreender essas transformações é preciso explorar rapidamente o modelo de regulação do mercado e das relações de trabalho que se consolidou no Brasil na década de 40 do século XX. A orientação desse modelo reproduziu, de forma modificada, aquela que marcou a lei de 1879, que refutou qualquer direito de organização aos trabalhadores em regime de colonato e parceria. Essa situação de constrangimento foi posteriormente estendida aos trabalhadores industriais com a Lei Adolfo Gordo de 1907, que legitimou a expulsão do país de estrangeiros que atentassem contra a ordem pública.

Gráfico 3: Salário Mínimo e Salário Médio Industrial

do Pessoal Ligado à Produção (Brasil, 1940)

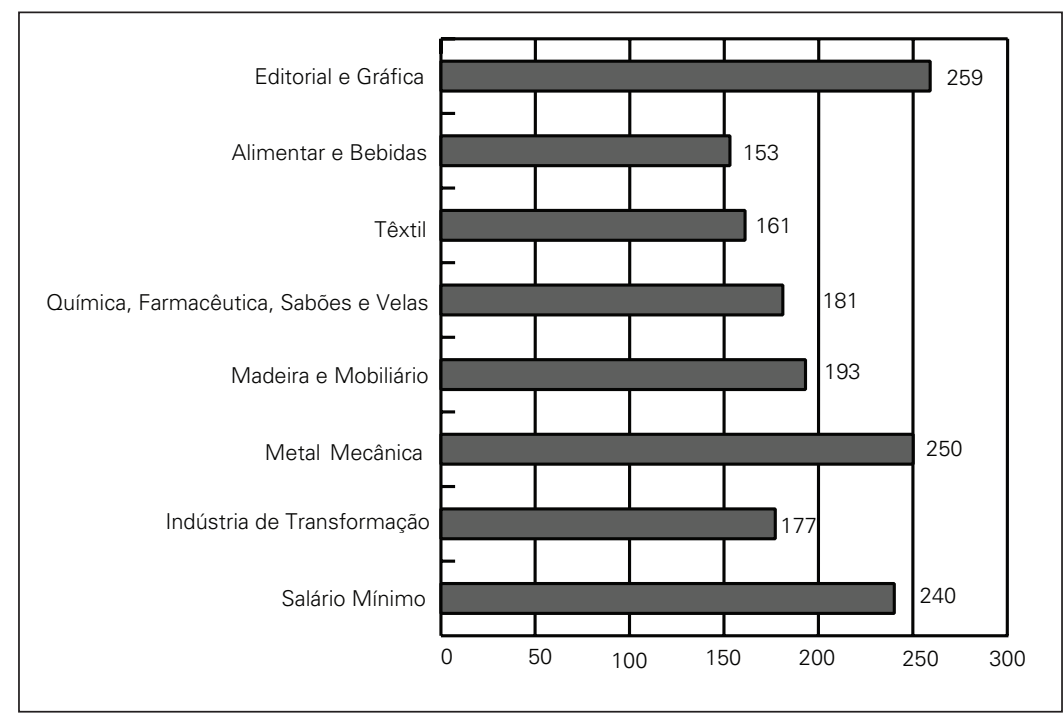

Fonte: Estatísticas Históricas do Brasil, IBGE; Boletim do Banco Central, Banco Central do Brasil. Elaboração do autor. 
Sistematicamente o Estado combateu a ação sindical durante as três primeiras décadas do século passado. Somente na década de 30 ele iniciou o reconhecimento da organização sindical, entretanto, de maneira tutelada. Também, naquela década foram reconhecidos alguns direitos sociais do trabalho, bem como ganharam impulso os sistemas previdenciários por categorias de trabalhadores.

Entre 1940 e 1942, foi estabelecida uma ampla regulação do mercado e das relações de trabalho. Foram instituídos o salário mínimo e toda uma legislação de regulação das relações de trabalho (Consolidação das Leis do Trabalho, CLT) para o mercado de trabalho não agrícola, tendo essa última promovido uma organização sindical consentida pelo Estado.

Considerado o mercado de trabalho da época, caracterizado por $75 \%$ da ocupação vinculada às atividades agrícolas, pode-se afirmar que a legislação instituída representava um quase nirvana para os trabalhadores brasileiros, ao prometer um amplo conjunto de direitos a uma população completamente desprovida de qualquer proteção social. Isso é refletido, inclusive, quando se compara o valor do primeiro salário mínimo com aqueles dos salários médios industriais prevalecentes em 1940. Somente os trabalhadores das indústrias Editorial e Gráfica e Metal Mecânica auferiam salários médios um pouco superiores ao salário mínimo.

Instituída legalmente a remuneração de base do mercado de trabalho e estabelecido um sistema de proteção social, era necessário garantir os mecanismos que as transformassem em instrumentos efetivos de regulação do mercado e das relações de trabalho. Isto é, era preciso promover a difusão desse modelo de regulação a todos os contratos de trabalho.

É sobre essa questão que recai a permanência modificada da Lei de 1879 . O governo Vargas impediu formalmente que a ação sindical estabelecesse uma dinâmica autônoma da negociação coletiva que pudesse favorecer a difusão dos direitos legais. Ao tutelar os sindicatos, transformou a negociação coletiva em um instrumento burocrático, reconhecendo o direito privado das empresas na gestão cotidiana das relações de trabalho. Ao mesmo tempo que articulou toda uma extensa regulação do mercado e das relações de trabalho, Vargas atuou no sentido de coibir os mecanismos que pudessem transformá-la em realidade para os trabalhadores brasileiros.

Se, por um lado, a regulação pública era virtual para o ordenamento do mercado de trabalho industrial em expansão, ao garantir a subordinação e a disciplina da força de trabalho necessárias ao processo de acumulação que se consolidava desde o início dos anos 30, ela, por outro, não efetivou a base de direitos nesse mercado (Oliveira, 1975).

O peso limitado dos trabalhadores urbanos organizados naquele mercado de trabalho favoreceu a ação repressiva e de manipulação política da Era Vargas, garantindo que a posição contraditória do modelo de regulação não se constituísse em entrave ao seu projeto político. Ao contrário, ele se aproveitou dessa contradição para vender a imagem de "pai dos pobres".

O processo de industrialização sob o véu desse modelo político de regulação ocorreu com a reprodução sistemática de um mercado de trabalho com uma baixa 
efetividade da proteção social. Ao final do longo período de industrialização 193080, aproximadamente metade da população ocupada não tinha acesso ao sistema de proteção social constituído em 1940. Em grande medida, essa situação foi viabilizada pela recorrência de governos autoritários que combateram violentamente a ação sindical e as tentativas de efetivação de uma regulação social mais ampla para o mercado e as relações de trabalho no Brasil. Esse movimento foi favorecido, ademais, pela recorrência de uma excessiva disponibilidade de força de trabalho constituída na segunda metade do século XIX, que jogou permanentemente contra a organização sindical e que garantiu baixos salários para o processo de industrialização.

Assim, o baixo grau de proteção social reproduziu um mercado de trabalho pouco institucionalizado, marcado pela presença extensa de contratos de trabalho estabelecidos informalmente. Esse é o tema que dominará as análises sobre o mercado de trabalho brasileiro nos anos 60 e 70. A questão debatida não era a do desemprego, mas aquela do problema de emprego expresso na recorrente informalidade que acompanhou a trajetória de crescimento de longo prazo do país entre 1930 e 1980. Esse debate também constituiu os elementos para a discussão da péssima distribuição de renda associada àquele processo de desenvolvimento (Salm e Eichemberg, 1989).

Resumidamente, pode-se afirmar que o modelo de regulação refletia o grande descompasso entre o forte desenvolvimento econômico e o quase ausente desenvolvimento social. $\mathrm{O}$ modelo de regulação era virtuoso ao desenvolvimento econômico, ao não permitir o estabelecimento de mecanismos redistributivos, os quais dependiam da existência de uma política social efetiva. Esta é uma particularidade da experiência brasileira, que a distancia tanto daquela conhecida pelos países europeus como daquela percorrida por países latino-americanos, que conheceram um maior avanço do processo de industrialização - Argentina, Chile e México.

\section{ANOS 80, UMA DÉCADA DE TRANSIÇÃO E CRISE COM A EMERGÊNCIA DO DESEMPREGO}

A retomada da cena política pelo movimento sindical e a perda de legitimidade do projeto militar autoritário, na segunda metade da década de 70 , abriram um novo período de mudanças políticas importantes no país.

O crescimento da ação sindical foi acompanhado da reivindicação por um desenvolvimento econômico atrelado ao desenvolvimento social. A democratização do país apareceu como repulsa ao modelo militar autoritário e, também, como perspectiva de transformação do quadro social desfavorável que caracterizava o país depois de tantos anos de crescimento econômico. O peso da tradição autoritária na trajetória política do país induziu a reconstituição de um movimento sindical mais politizado, com demandas que não se circunscreveram às modificações no modelo de regulação do mercado e das relações de trabalho. Essa característica da ação sindical foi violentamente reprimida pelo governo militar autoritário da época, induzindo uma resposta dos trabalhadores em favor de uma representação 
política própria. Nascia assim o Partido dos Trabalhadores. A construção do PT foi marcada pela divisão do movimento sindical, que na primeira metade dos anos 80 construiu duas Centrais Sindicais.

A reorganização do movimento sindical foi surpreendida por uma crise econômica sem precedentes na história do país. As novas orientações de política econômica dos Estados Unidos, adotadas a partir de 1979, interromperam o fluxo de crédito externo que havia viabilizado o crescimento acelerado da economia brasileira dos anos 70. Pela primeira vez, o país conheceu uma crise explícita de seu segmento industrial. Até então, a economia brasileira havia vivenciado momentos curtos de retração, como aquele provocado pela crise de 29 durante os primeiros anos da década de 30, ou como aquele induzido pela modernização tecnológica ocorrida na indústria têxtil na primeira metade dos anos 50 ou como o causado pelo fim do Plano de Metas (1956-60) nos primeiros anos da década de 60.

A crise dos anos 80 provocou uma queda aproximada de $25 \%$ na Produção Industrial acompanhada por uma redução semelhante do nível de emprego industrial. Foi uma novidade para o país a ocorrência de um desemprego em massa oriundo da Indústria de Transformação. Nos anos de 1981 e 1982, o desemprego transformou-se em uma nova realidade para o país, chegando atingir mais de $20 \%$ da População Economicamente Ativa da Grande São Paulo (Sabóia, 1986).

A emergência do desemprego não foi observada de maneira homogênea no território nacional. Sua ocorrência ficou, em grande medida, restrita às zonas urbanas com maior densidade industrial, que possuíam inclusive um mercado de trabalho com maior presença da regulação social existente. É por esse motivo que a Grande São Paulo despontou também como o centro da crise social. Boa parte dos desempregados era originária de grandes empresas industriais, possuindo a situação de assalariamento como única trajetória realizada no mercado de trabalho. Para a grande maioria, a perda do emprego se traduziu, em um primeiro momento, na situação de desemprego aberto. Entretanto, a falta de um sistema de seguro-desemprego induzia que, posteriormente, a situação de desocupação fosse associada a algum tipo de atividade irregular que pudesse viabilizar a própria sobrevivência ou financiar a procura de um novo posto de trabalho.

Pode-se afirmar que a limitada institucionalidade do mercado e das relações de trabalho explicou a emergência do fenômeno do desemprego com características complexas. O crescimento do desemprego aberto foi acompanhado de outras formas de desemprego, as quais, muitas vezes, são difíceis de serem diferenciadas da situação de precariedade que predomina no trabalho informal.

Ao contrário da experiência européia, em que a complexidade do desemprego pode ser associada ao processo de corrosão da regulação social, é possível afirmar que a maior complexidade do desemprego na experiência brasileira nasceu justamente da ausência histórica daquela regulação. Ela explica por que o problema de emprego se distancia acentuadamente da situação de desemprego clássica, debatida por Keynes nos anos 30 ou que continua a dominar certos países europeus que pouco modificaram sua regulação social - Dinamarca e Suécia.

Esse distanciamento não ganhou maior dimensão no Brasil dos anos 80, graças 
a certas características que marcaram a trajetória política do país. O processo de democratização empreendido definiu uma redefinição institucional divergente daquela predominante na América Latina e mesmo em boa parte dos países desenvolvidos. Em vez de se incorporar ao espírito da contra-revolução conservadora, a sociedade brasileira trilhou uma trajetória de reestruturação orientada pela esperança de construção de um Estado de bem-estar social no país. Assim, ela coroou o período de democratização com uma nova Constituição Nacional que definiu um ordenamento legal com o objetivo de promover um desenvolvimento econômico interno com desenvolvimento social. As grandes inovações da Constituição de 1988 centraram-se na construção de uma política social efetiva. Estabeleceu as bases para um desenvolvimento centrado no mercado interno que pudesse ser caracterizado pela justiça social. Assim, esperava-se que os anos 90 fossem marcados pela retomada do crescimento com geração de emprego e distribuição de renda.

Apesar da situação de instabilidade que caracterizou a década, marcada por movimentos curtos de recuperação seguidos de outros de recessão em um contexto de alta inflação, chegou-se ao final do período com uma taxa de desemprego relativamente baixa. Após os anos de recessão de 1981 a 1983, os movimentos curtos de recuperação permitiram a recomposição do nível de emprego industrial, o qual, em 1989, era similar àquele de 1980. Se o desemprego foi a grande marca dos anos de recessão do início da década, foi a piora da distribuição de renda que constituiu a principal característica para o conjunto do período.

Para a década de 90, a sociedade brasileira tinha a esperança de retomar a trajetória de crescimento passado, considerando os anos 80 como um período de transição na construção de um país menos desigual.

\section{ANOS 90: ENFIM A CONTRA-REVOLUÇÃO CONSERVADORA}

Os resultados dos anos 90 se distanciam totalmente daqueles prognosticados no final da década anterior. Em lugar de uma retomada econômica com geração de emprego e distribuição de renda, o país conheceu mais um período de quase estagnação, desemprego e aumento da desigualdade social.

Esse processo somente pode ser compreendido se considerado o resultado da eleição nacional de 1989. Após quase trinta anos, o país realizou novamente uma eleição presidencial através do voto direto.

Durante a campanha, duas posições políticas foram sendo consolidadas, as quais organizaram todo o debate desenvolvido no segundo turno das eleições. Uma, defendida por partidos de centro-esquerda e de esquerda, mantinha total aderência aos propósitos firmados na Constituição de 1988. Uma outra, já presente durante os trabalhos da Constituinte, encaminhava proposta que refutava boa parte dos propósitos inscritos no marco legal recentemente aprovado.

A vitória da segunda posição legitimou uma mudança radical nos rumos econômico e social do país para a década de 1990. Seu principal argumento afirmava que o período de industrialização protegida - 1930-80 — havia produzido uma 
sociedade distorcida, marcada por grandes privilégios para alguns e penúria para muitos. Os maiores privilegiados eram os trabalhadores das grandes empresas públicas e privadas e do Estado, situação garantida pela regulação social vigente no país desde 1940. A posição de privilégio decorria da total falta de proteção social em que era mantida a maioria da população.

De fato, a posição vitoriosa reproduzia o discurso que vinha ganhando predominância tanto nos países desenvolvidos como em desenvolvimento desde o final dos anos 70. Esse discurso associava a crise ao sistema de proteção econômica e social existente. Desregulamentação e flexibilização constituíam os fundamentos da proposta, consideradas como os instrumentos decisivos para resolver os problemas econômicos e sociais mais complexos.

Nessa perspectiva, os problemas de emprego no Brasil tinham raiz no modelo de regulação social existente, o qual havia sido ampliado pela Constituição de 1988. Para completar, a posição conservadora afirmava que a nova Constituição nada mais representava que uma chancela ao atraso do país em relação aos novos ventos da globalização.

Naquilo que se refere ao problema de emprego, a nova orientação inverteu os termos do debate até então empreendido. Como se procurou mostrar anteriormente, tal problema no Brasil tem raízes no processo de formação do mercado nacional de trabalho. Essas raízes foram reafirmadas pelo modelo de regulação social estabelecido na década de 40 . Até os anos 80 , o problema de emprego jamais foi associado à suposta disfunção da regulação social existente, mas à sua limitada estruturação e eficácia. A Constituição Nacional de 1988 reafirmou essa perspectiva ao criar instrumentos que pudessem ampliar a regulação do mercado e das relações de trabalho no país.

Gráfico 4: Indicadores Gerais: PIB, População em Idade Ativa e População Economicamente Ativa (Brasil, 1990-1999)

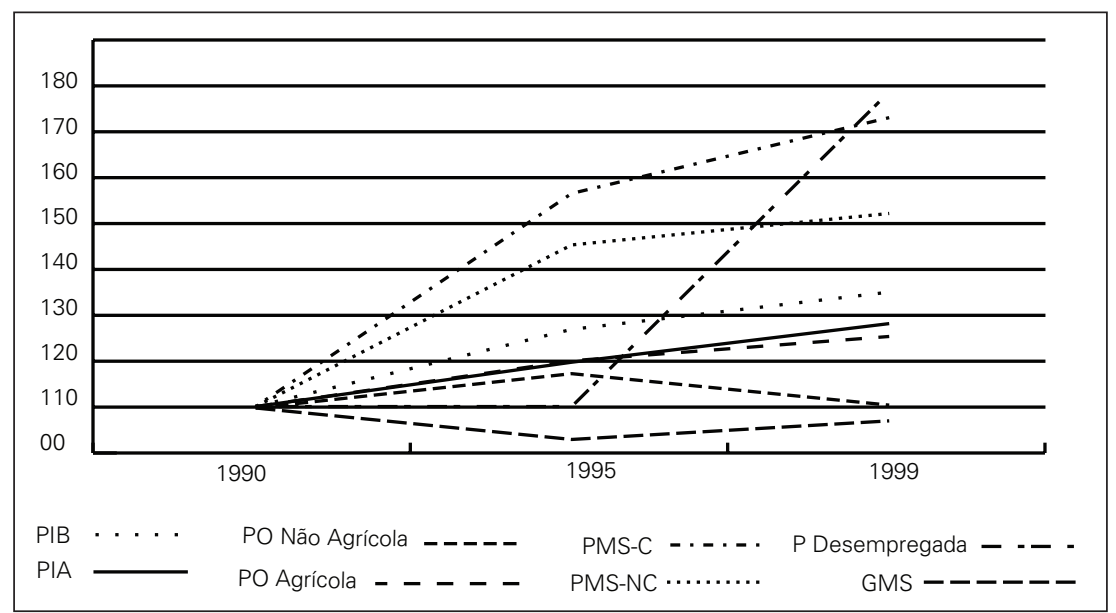

Fonte: Estatísticas Históricas do Brasil, IBGE; Boletim do Banco Central, Banco Central do Brasil. Elaboração do autor. 
Desprezando os elementos estruturais do problema do emprego, posição que permitia desconsiderar as raízes históricas do problema social no país, a política conservadora assume o discurso e as diretrizes recentes que foram dominando as políticas públicas nos países desenvolvidos e em desenvolvimento. Nessa perspectiva, o problema de emprego passa a ser, sistematicamente, vinculado ao funcionamento inadequado do mercado de trabalho, explicado pela regulação excessiva das relações de trabalho imposta pela proteção social.

A política adotada, a partir do início dos anos 90, permitiu uma forte exposição externa da base produtiva local, implementou um novo receituário de política econômica e buscou enfraquecer o poder de barganha dos segmentos organizados da sociedade, na esperança de reduzir a resistência aos projetos de flexibilização do sistema de proteção social inscrito na Constituição de 1988.

A nova política impôs imediatamente uma grave recessão econômica ao país. A produção e o emprego industriais caíram, aproximadamente, $25 \%$ com a duplicação do desemprego no espaço de um ano. A ausência de um ciclo de crédito internacional, que garantisse a entrada de capitais com o objetivo de financiar o déficit nas contas externas, impediu a continuidade da política por um prazo mais longo, impondo-lhe um período de compasso de espera a partir de 1991. Essa situação foi mantida até o segundo semestre de 1993. O impeachment do presidente Fernando Collor, resultado de uma grande mobilização nacional, dificultou ao novo presidente empossado dar imediatamente continuidade à política implementada desde 1990. Somente no final de 1993, ela foi retomada. Ao longo de 1994 um novo plano econômico foi adotado, com diretrizes fiéis às já presentes no anterior, cujo sucesso esteve estreitamente ligado a uma grande injeção de recursos externos.

Os efeitos do Plano Real sobre o mercado de trabalho foram desastrosos, chancelando uma nova relação entre dinâmica econômica e emprego. Apesar do impacto positivo inicialmente criado pelo Plano sobre o desempenho da atividade econômica, observou-se uma contínua deterioração do nível de emprego, acompanhada de uma tendência sustentada de crescimento do desemprego.

Esse aumento do desemprego trouxe grande desconforto para o governo. $\mathrm{O}$ Plano Real tinha recebido um grande apoio da população, viabilizando a vitória nas eleições presidenciais daquele que havia pilotado sua implantação. Após mais de uma década de inflação elevada, o país aplaudia a estabilização dos preços. De imediato, ela permitiu o fim de um processo contínuo de corrosão da renda dos assalariados e viabilizou, novamente, os mecanismos de crédito ao consumo.

O governo aproveitou desse fato para realizar uma política de desqualificação da situação de desemprego (Dedecca, 1996 e 1988), argumentando que as taxas não refletiam a realidade do mercado de trabalho brasileiro. Afirmava ser verdade a queda do emprego industrial, mas apontava o crescimento do emprego de serviços. Completava seu argumento, ressaltando que essas mudanças na estrutura de emprego eram inevitáveis e que acompanhavam as transformações observadas no mundo globalizado.

A crítica a uma suposta situação de desemprego elevado era justificada no 
argumento de crescimento do emprego nas atividades de serviços, que na sua maioria é caracterizado pela falta de proteção social. Para o governo, parte dos ocupados estavam sendo computados com desempregados, devido à falta de qualidade de seus empregos. O setor informal, que desde o início de sua discussão foi considerado lócus precário de inserção produtiva da população, passou a ser valorizado pelo governo.

Assim, o governo concluía que era necessário mudar as metodologias de mensuração do desemprego e, em especial, alterar o modelo de regulação pública do mercado e das relações de trabalho. De fato, o foco principal do governo era o modelo de regulação. Afinal, destoando de outros países da América Latina, o Brasil havia buscado ampliar a regulação social durante os anos 80 .

Para o governo, o modelo de regulação havia gerado uma segmentação do mercado de trabalho, permitindo que uma parcela restrita obtivesse privilégios às custas da falta de proteção da grande maioria. Ao impedir a concorrência no mercado de trabalho, a regulação social havia possibilitado o estabelecimento de nichos ocupacionais. Era preciso, portanto, quebrar essa situação de privilégio.

Aqui reside a grande questão para o debate sobre o desemprego no Brasil. Nos anos 90, essa perspectiva de política conseguiu inverter os termos do debate, desprezando as raízes históricas da formação do mercado nacional de trabalho e suas implicações para sua estruturação.

A posição predominante defendeu sistematicamente que o modelo de regulação era a causa dos problemas presentes. Desse ponto de vista, a regulação social passou a ser vista como um entrave para a modernização do país. Apesar dos esforços da política econômica em reorganizar positivamente o país, seus efeitos eram limitados pela política social. Nesse sentido, ganhou força no diagnóstico do governo a necessidade de flexibilizar o modelo de regulação com o objetivo de torná-lo aderente às novas condições de funcionamento da economia.

Para melhor discutir esse ponto, é preciso fazer uma reflexão, mesmo que rápida, sobre a dimensão da mudança que o Brasil conheceu em termos de sua dinâmica econômica e seus efeitos sobre o mercado de trabalho nos anos 90. Para facilitar a análise desse ponto, uma visão esquemática do processo é adotada, mesmo considerando os riscos que uma postura desse tipo em geral traz.

Entre 1930 e 1990, o modelo econômico prevalecente no país esteve centrado no desenvolvimento da base produtiva e do mercado internos. Nas segundas metades das décadas de 50 e 70, planos de desenvolvimento permitiram que o país realizasse grandes saltos em seu desenvolvimento industrial, conseguindo estabelecer uma estrutura bastante complexa com um setor de bens de capital razoavelmente desenvolvido.

A crise dos anos 80 praticamente interrompeu o fluxo de recursos externos para o país, exigindo ainda que fossem gerados superávits comerciais elevados para cumprir os altos encargos da dívida externa. Essa situação de constrangimento induziu uma elevação acentuada do grau de proteção da estrutura local em relação à economia internacional. Ao final da década, as importações nacionais se circunscreviam, em grande medida, a dois produtos: petróleo e trigo. Quanto aos 
produtos industriais, quase todo padrão de consumo era produzido no país. Essa situação se diferenciava enormemente daquela encontrada no final dos anos 70 , quando o país possuía uma pauta de importação bastante mais diversificada e tinha sua estrutura produtiva mais exposta à concorrência internacional.

Quadro 1: Implicações da Dinâmica Econômica sobre o Mercado de Trabalho

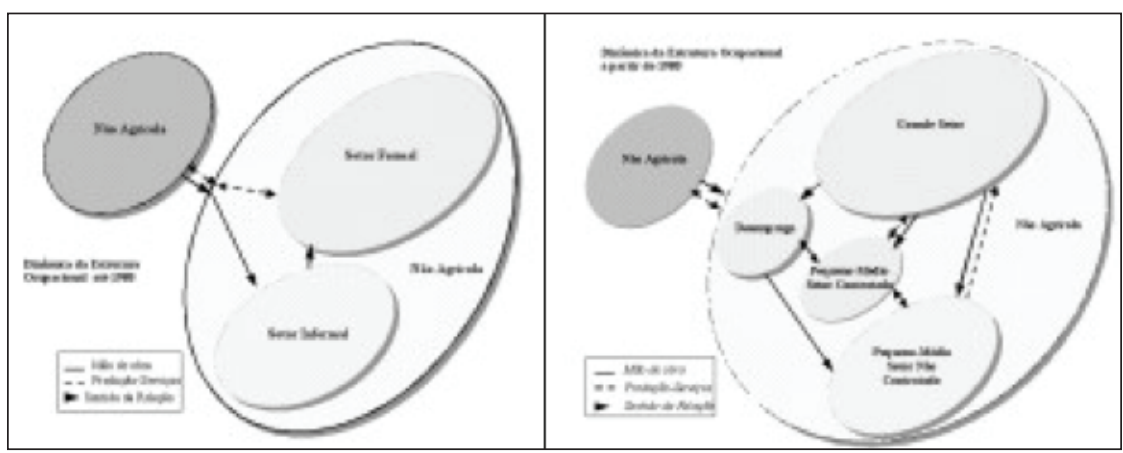

O padrão de industrialização caracterizava-se por uma forte integração e verticalização das grandes empresas. O nível de subcontratação existente era extremamente baixo. Ademais, as empresas internacionais mantinham muito pouca relação produtiva com suas matrizes, podendo-se afirmar a ocorrência de uma grande autonomia de seus processos produtivos locais. Os anos 80 reforçaram essa característica da estrutura industrial brasileira.

No que se refere ao mercado de trabalho, o processo de industrialização lhe imprimiu uma particular dinâmica. A ocorrência de um longo período de crescimento e a existência de uma estrutura fundada em empresas bastante integradas explicavam o movimento convergente entre crescimento da produção e do emprego. Durante o período 1930-80, uma elasticidade produto-emprego elevada conformou uma característica recorrente do desenvolvimento.

Apesar da ponderável capacidade de geração de novos empregos da economia, o país viveu permanentemente com um problema de emprego. A razão básica deveu-se ao excedente de mão-de-obra criado pelo particular processo de formação do mercado de trabalho livre e o estabelecimento da estrutura fundiária ocorridos na segunda metade do século XIX.

O problema de emprego aparecia com a reprodução sistemática de um amplo setor informal. A migração rural-urbana criou permanentemente grandes contingentes de mão-de-obra, os quais puderam ser só parcialmente absorvidos pelo grande setor da economia, formado pelas grandes empresas e o setor público. Como não era característica do grande setor a expulsão de trabalhadores, o problema de emprego não aparecia na forma de desemprego. Essa dinâmica do mercado de trabalho encontra-se apresentada de modo sintético no Quadro 1.

Essas dinâmicas da estrutura produtiva e do mercado de trabalho foram rompidas na década de 90. A diretriz de política econômica que se implementa a partir de 1990, se estabelecendo politicamente com êxito em 1994, provocou um proces- 
so violento de reestruturação econômica. De acordo com essa política, o processo de industrialização havia produzido uma economia protegida e atrasada, havendo a necessidade de um processo de abertura externa que expusesse à concorrência externa a base produtiva local, considerada como única via possível para a modernização econômica.

Além da abertura, a política conservadora compreendia que a proteção deviase a presença de um Estado paternalista, que havia criado uma economia estatizada. Devia-se, portanto, proceder-se uma privatização de várias funções do Estado. No campo da política social, defendia que elas fossem modificadas com o objetivo de transformar seu caráter universal em focal.

Se em um primeiro momento a política não teve êxito, observa-se que, em 1994, seu objetivo é alcançado. Graças à existência de um grande fluxo de recursos externos, realiza-se uma racionalização substantiva da estrutura industrial caracterizada por uma rápida internacionalização de sua propriedade, o estabelecimento de uma dependência produtiva de insumos importados e o suprimento de uma parcela considerável do padrão de consumo por produtos estrangeiros. O resultado imediato foi uma explosão do déficit em conta corrente, um comportamento medíocre do nível de produção industrial e uma contração acentuada do emprego no grande setor da economia.

Essa dinâmica produziu a explosão do desemprego conjuntamente ao aumento da informalidade no mercado de trabalho. Para um crescimento da PEA de 13 milhões de pessoas, entre 1990 e 1999, o grande setor expulsou 1 milhão, o pequeno-médio setor contratado absorveu 1,9 milhão e o pequeno-médio setor não contratado incorporou 6,2 milhões. Ao mesmo tempo, mais 5,5 milhões de pessoas se incorporavam ao desemprego ${ }^{2}$.

A expulsão de trabalhadores do grande setor passa a ser uma característica recorrente. A internacionalização da base produtiva criou uma integração produtiva estreita entre as empresas locais e suas congêneres no mercado internacional. Agora a planta produtiva brasileira é ponto de uma rede gerenciada pelas matrizes das empresas multinacionais. O país perdeu, portanto, capacidade local de monitoramento dessas plantas. A incorporação dessas plantas a uma rede internacionalizada em um contexto de ponderável exposição externa provocou um processo recorrente de racionalização produtiva com impactos negativos e permanentes

\footnotetext{
2 Dadas as características metodológicas da Pesquisa Nacional por Amostra de Domicílios, PNAD-IBGE, é possível analisar a estrutura ocupacional não agrícola segundo alguns aspectos de organização do trabalho e sua relação com a estrutura produtiva. É possível analisar a relação de subordinação ou não do trabalho, o tamanho do empreendimento no qual ele se realiza, o setor de atividade. A pesquisa definiu a organização da estrutura ocupacional a partir dessas variáveis em três segmentos: grande setor — formado pela ocupação das grandes empresas e o Estado; pequeno setor contratado - constituído pelas ocupações em empreendimentos que destinam sua atividade para consumo em outro empreendimento; e pequeno setor não contratado — organizado pela ocupação em empreendimentos que destinam sua atividade para consumo das famílias e/ou dos indivíduos. Uma análise mais detalhada dessa metodologia pode ser encontrada em Dedecca (2000).
} 
sobre o nível de emprego local. Essa nova dinâmica da estrutura produtiva e seus efeitos sobre o mercado de trabalho encontram-se sintetizados no Quadro 1.

Entretanto, um aspecto particular dessa dinâmica merece uma atenção maior. Se considerado o pequeno setor, percebemos que, apesar de substantivo, o crescimento do segmento contratado foi muito inferior ao encontrado para o segmento não contratado.

De acordo com a política conservadora, a mudança da estrutura ocupacional tinha por direção os serviços modernos, em geral prestados para consumo das empresas. É sobre esse ponto que se desenvolveu toda a discussão sobre terceirização e subcontratação. Argumentos foram apresentados para justificar a emergência de uma estrutura econômica menos concentrada, marcada pela presença extensa e importante dos pequenos e médios empreendimentos. São esses mesmos argumentos que defenderam a flexibilização da regulação social, pois a ocupação nesses empreendimentos não se caracteriza pela rigidez presente no emprego assalariado.

Independentemente da consistência desses argumentos veiculados pela visão conservadora, a experiência brasileira mostra que nos anos 90 não foram essas ocupações que caracterizaram a mudança do mercado de trabalho. A grande maioria das ocupações foi criada pelos pequenos empreendimentos voltados para o consumo das famílias e indivíduos, sendo que a principal característica dessas ocupações é o baixo rendimento e a pouca qualificação, justificadas pela baixa produtividade obtida nesse tipo de atividade. Quando considerado somente o pequeno setor, observa-se que o emprego doméstico aparece dentre as ocupações com maior crescimento.

Esse quadro analítico permite explicitar a pouca consistência do diagnóstico conservador sobre o problema do emprego no Brasil. A nova dinâmica econômica, estabelecida a partir do início dos anos 90, jogou sistematicamente contra o mercado de trabalho. A baixa capacidade de geração de novas oportunidades de emprego, em um contexto de restrita regulamentação social, induziu que tal problema se manifestasse principalmente pela proliferação de ocupações de baixos rendimento e qualificação. Nesse contexto, pode-se dizer que o problema de emprego continuou extrapolando a situação de desemprego. As pesquisas que mensuram o desemprego tendem, portanto, a ser conservadoras em relação à extensão do problema do emprego no país.

Ademais, explicita-se que a crise do mercado de trabalho nos anos 90 não teve como raiz a regulação social existente. Foi justamente seu desenvolvimento limitado que explicou a recorrência da informalidade na estrutura ocupacional brasileira. A história do trabalho no Brasil é suficientemente perversa para produzir, ainda hoje, um quadro desfavorável de estruturação do mercado nacional de trabalho. O processo de industrialização 1930-90 não resolveu os problemas estruturais desse mercado. A política atual de reestruturação econômica tem agravado rapidamente tais problemas. Pode-se afirmar que esses problemas não decorrem de uma possível efetividade da regulação social. Ao contrário, eles são determinados pela recorrência de uma posição política conservadora no Brasil que manteve sob acicate a regulação social. 
Nesse sentido, o problema de emprego no Brasil se diferencia enormemente daquele encontrado nos países da Europa Central. Nesses mercados, a regulação social produziu uma progressiva homogeneização da proteção ao emprego, de modo a condicionar, em um primeiro momento, o problema de emprego à situação de desemprego aberto. Somente com as políticas de flexibilização é que o problema de emprego ganhou uma nova dimensão (Cerc-Association, 2001). A falta de um colchão amortecedor, cumprido pelo setor informal, e a importância histórica do trabalho protegido criaram movimentos de exclusão social de modo complementar à situação de desemprego. A exclusão social é um sinal de ausência de brechas no mercado de trabalho, que pudessem acomodar precariamente aqueles que não conseguem um emprego protegido. Essa ausência deve-se ao papel da regulação social cumprida no desenvolvimento desses países.

É grande a distância do Brasil em relação às experiências dos países da Europa Central. A ocorrência de um desenvolvimento econômico descasado de um desenvolvimento social garantiu a consolidação de um mercado de trabalho heterogêneo em termos de proteção social. Sistematicamente, o problema de emprego foi sendo acomodado na informalidade. A reestruturação dos anos 90 imprimiu uma nova dinâmica à economia e ao mercado de trabalho. O movimento tradicional de informalidade foi complementado pelo desemprego. A recorrência desse em longo prazo não se converte em exclusão social, nos termos pensados nos países da Europa central, mas em trabalho precário informal.

É por isso que afirmamos que a posição conservadora erra totalmente seu diagnóstico sobre o problema de emprego no Brasil. Entretanto, sua legitimidade política lhe garantiu a implementação de políticas convergentes com esse diagnóstico que, como procuramos apontar nesse ensaio, tem produzido um agravamento substancial do problema de emprego no país.

\section{REFERÊNCIAS BIBLIOGRÁFICAS}

CANO, W. (1990) Raízes da industrialização brasileira, São Paulo: Hucitec.

CARVALHO FRANCO, M. S. (1983) Homens livres na ordem escravocrata, São Paulo: Kairós.

CERC-ASSOCIATION (2001) Des chomages des plus en plus “invisibles”, La Note de Cerc Association 10, Paris: Cerc-Association.

DEDECCA, C. S. (1996) “Desemprego e regulação hoje no Brasil”. Cadernos de Discussão 20, Campinas, Unicamp.Ie-Cesit.

DEDECCA, C. S. (1998) “O desemprego e seu diagnóstico hoje no Brasil”. Revista de Economia Politica, São Paulo, vol. 16, n 1.

DEDECCA, C. S. (2000) Reorganisation Economique, Qualification et Absortion de Main-d'oeuvre, Seminaire International, Paris: Greidt.

FANO, E. (1979) “Crisi e Ripresa Economica nel Bilancio del New Deal” In: Crisi e Piano: le alternative degli anni trenta. Bari: Ed. de Donato, 1979.

FURTADO, C. (1977) A formação econômica do Brasil, Rio de Janeiro: Editora Nacional.

HOLLOWAY, T. H. (1984) Imigrantes para o café, Rio de Janeiro: Paz e Terra.

KEYNES, M. (1975) Essays on the John M. Keynes, vol. 9. Cambridge: Cambridge University Press.

LAMOUNIER, M. L. (1988) Da escravidão ao trabalho livre. Campinas: Papirus. 
MELLO E CASTRO, E. (1984) O Norte agrário e o Império, 1871-1889. Rio de Janeiro: Editora Nova Fronteira/Instituto Nacional do Livro.

MISHELL; BERNSTEIN; SCHIMITT (2001) The State of Working America 2000-01. Washington DC: Economic Policy Institute.

OLIVEIRA, F. (1975) “A economia brasileira: crítica da razão dualista”. Seleções Cebrap, n 1, São Paulo: Cebrap.

POLANY, K. (1978) A grande transformação. Rio de Janeiro: Campus.

PUGLIESE, E. (1993) Sociologia della Desoccupazione. Milano: Il Mulino.

SABÓIA, J. M. (1986) “Transformações no mercado de trabalho no Brasil durante a crise: 1980-1983”. Revista de Economia Política, 6(3), São Paulo: Brasiliense.

SALAIS, R.; BAVAREZ, N.; REYNAUD, B. (1986) L'Invention du Chômage. Paris: PUF.

SALM, C.; EICHEMBERG, L. C. (1989) "Tendencia de integración en el mercado de trabajo brasileño". Revista de la Cepal 36, Santiago de Chile: Cepal.

SORRENTINO, C. (1993) "International comparisons of unemployment indicators". Monthly Labor Review, Washington, DC, March.

STOLCKE, V.; HALL, M. (1983) "A introdução do trabalho livre nas fazendas de café de São Paulo". Revista Brasileira de História, 5(6), São Paulo: Marco Zero.

THOMPSON, E. P. (1980) The Making of the English Making Class. London: Penguin. 